\title{
Contest "Bebras" on Informatics in Russia and Belarus
}

\author{
Sergei N. POZDNIAKOV ${ }^{1,2}$, Iryna F. KIRYNOVICH ${ }^{3}$, \\ Ilya A. POSOV ${ }^{1,2}$ \\ ${ }^{1}$ Saint Petersburg State Electotechnical University \\ ul. Professora Popova 5, 197376 St. Petersburg, Russian Federation \\ ${ }^{2}$ Saint Petersburg State University \\ Universitetskaya nab. 7/9, 199034 St. Petersburg, Russian Federation \\ ${ }^{3}$ Belarusian Olympiad in Informatics \\ Contest "Bebras" on Informatics in Belarus \\ Belarusian State University of Informatics and Radioelectronics \\ Brovki 6, Minsk, Belarus, 220013 \\ e-mail:pozdnkov@gmail.com,kirinovich.irina@yandex.ru,iposov@gmail.com, \\ i.posov@spbu.ru
}

\begin{abstract}
The paper presents an experience of work with gifted schoolchildren in the field of informatics within the International Contest "Bebras". The idea of tasks that develops algorithmic or computational thinking is presented. The on-line Russian site of the contest and its coverage of schoolchildren of Russia and Belarus is demonstrated.
\end{abstract}

Keywords: Informatics, algorithmic and computational thinking, electronic educational resources.

\section{Introduction}

International educational collaboration in the form of intellectual contests of schoolchildren from different countries is developed within global communications. An example of such a collaboration is an intellectual contest on Informatics "Bebras" (2016), that was joined by the Russian Federation in 2012, and by Belarus in 2015.

One of the organizers of the contest Bebras is Valentina Dagiene (Lithuania, Vilnius University), a specialist of International Olympiad in Informatics. She founded Bebras contest in 2004 and now more than 40 countries all over the world participate in it. 


\section{Russian History of the Bebras Contest}

In 2004, the contest «Construct, Test, Explore» (CTE) was founded by the Center of Information Technologies in Education "CTE", Russia (2016). Its main feature was support of a long experimental-research activity with a model of some idea of the field of informatics or discrete mathematics, that still did not have a full theoretical solution, or its solution was hard (Ivanov et. al., 2004). In this contest participants got three virtual laboratories on one week, during which they could hold experiments in an interactive mode. The software tested a participant solution to comply with the statement and also assessed how close it was to the optimal according to criteria formulated in the statement.

In 2012, the team of CTE contest developers and organizers joined the organization of the BEBRAS contest, that had already been held in 19 countries. Previously, at the seminar at Gargano, Italy on 9-11 Oct, 2011 a declaration to use the format of this contest to unity mass contests in informatics for all countries had been adopted.

The Center for informatization of education "CTE" had already developed a system to hold various competitions, and used it to hold the Bebras contest in Russia.

\section{Tasks of the BEBRAS Contest}

In the Bebras contest, the work on tasks is the main tool, uniting its organizers in different countries, thanks to an annual seminar, that gathers representatives of more than 40 countries. During 4-5 days they discuss and correct tasks, presented by participating countries and participation candidate countries.

Different countries according to their traditions of informatics formation pay attention to different aspects of computational (or algorithmic) thinking, that results in the versatile set of tasks that demonstrates new aspects of informatics.

Tasks usually have a textual form analogous to a Kangaroo (Kangaroo in Russia, Institute of Productive Learning, RAE) (2016) competition in mathematics that appeared before. The difference is that there are less problems and a wrong answer (choice of a wrong answer from four presented) subtracts one third of the task's scores. The time to solve problems is about one hour. One may find detailed competition rules at http:// bebras.org and http://bebras.ru.

Tasks cover rounds for 1-2, 3-4, 5-6, 7-8, 9-11 grades. Everybody including teachers and schoolchildren have free access to collections of tasks of previous years.

Fig. 1 presents an example of a task, where participants get acquainted with an idea of pattern recognition based on a neural network. A statement presents a network that recognizes "chairs", "armchairs", "stools" with different weights for different features such as a presence of a "back", "arms", etc. The question is to find a furniture on the presented set, that will not be classified by the network.

It is important for participants to know whether their answer is correct, and to read the solution. Fig 2. demonstrates the view of the solution. 


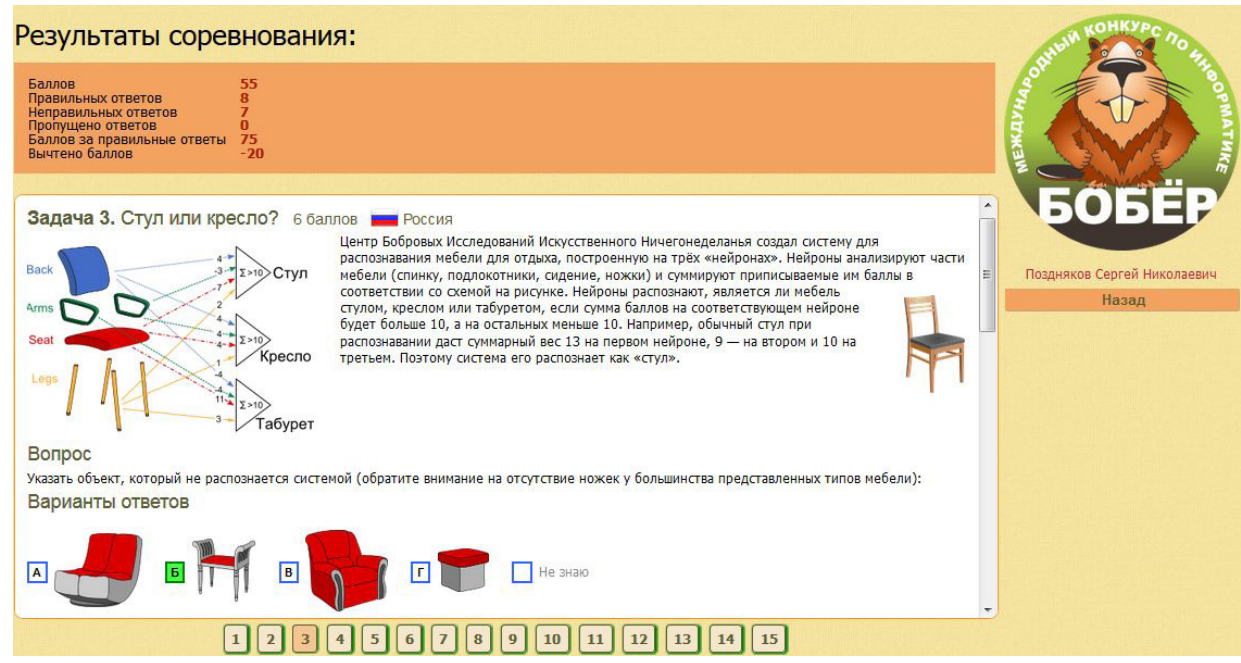

Fig. 1. An interface of a problem when a participant overviews results.

\section{Варианты ответов}

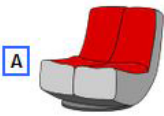

\section{Б}

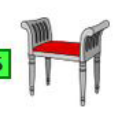

B
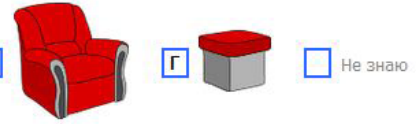

Правильный ответ: Б

\section{Решение}

- У старинного кресла есть спинка, подлокотники, сидение и нет ножек. Суммарные веса для различных типов мебели будут следующими: $4-3+7=8$ (стул), 4+4+4=12 (кресло), -4-4+11=3 (табурет). Таким образом, этот вид ме6ели будет признан креслом.

- у кресла-модерн есть спинка и сидение. Суммарные веса для различных типов мебели будут следующими: 4+7=11 (стул), 4+4=8 (кресло), -4+11=7 (табурет). Таким образом, этот вид мебели будет признан стулом.

○ у пуфика есть сидение. Суммарные веса для различных типов мебели будут следующими: 7 (стул), 4 (кресло), 11 (табурет). Таким образом, этот вид мебели будет признан табуретом.

о у банкетки есть подлокотники, сидение и ножки. Суммарные веса для различных типов будут следующими: $-3+7+2=6$ (стул), 4+4+1=9 (кресло), $-4+11+3=10$ (табурет). Таким образом, никакая из альтернатив не подходит для этого типа мебели.

Fig. 2. Explanation of the task about pattern recognition.

Here is an excerpt from the explanation of the task "Chair or an armchair?", how is it connected to informatics:

The system presented in the task is designed to classify any object in one of the four categories: chairs, armchairs, stools, or others. Neurons are simple components, that compute a sum and are "activated" if the result is greater than the threshold, corresponding to the neuron. This simple model is surprisingly close to what biologists know about real brain neurons. The numbers they sum are sometimes called input weights, because they correspond to the significance of each feature in the classification problem. For example, the presence of a sitting is a very important feature of a chair, while the presence of legs is almost irrelevant for armchairs.

Generally, a neuron is a compact way to express an otherwise complex rule. Since all the inputs are just binary (true/false) properties, you can see that by writing a table with all the possibilities. For the "Chair" neuron it is shown in Table 1. 
Now we present another example of a Bebras task. It was proposed by the Russian delegation to the Bebras tasks workshop in 2015, and it can be considered a typical Bebras task, because it was selected among the best tasks of that workshop (Dagiene and Futschek, 2008). It is a task about representation of information with graphs. We retain the original split of the task into sections, used in the workshop:

Title: Beaver the alchemist.

Body: Beaver the Alchemist can convert objects into other objects. He can convert:

1. Two clovers into a coin.

2. A coin and two clovers into a ruby.

3. A ruby and a clover into a crown.

4. A coin, a ruby, and a crown into a kitten.

After the objects have been converted to another object, they disappear. (see Fig 3)

Table 1

Table of variants for the task "A chair on an armchair?"

\begin{tabular}{|c|c|c|c|c|c|c|}
\hline & Back & Arms & Seat & Legs & Sum & Classification \\
\hline \multirow[t]{17}{*}{ Weights } & 4 & -3 & 7 & 2 & & \\
\hline & 0 & 0 & 0 & 0 & 0 & Other \\
\hline & 0 & 0 & 0 & 1 & 2 & Other \\
\hline & 0 & 0 & 1 & 0 & 7 & Other \\
\hline & 0 & 0 & 1 & 1 & 9 & Other \\
\hline & 0 & 1 & 0 & 0 & -3 & Other \\
\hline & 0 & 1 & 0 & 1 & -1 & Other \\
\hline & 0 & 1 & 1 & 0 & 4 & Other \\
\hline & 0 & 1 & 1 & 1 & 6 & Other \\
\hline & 1 & 0 & 0 & 0 & 4 & Other \\
\hline & 1 & 0 & 0 & 1 & 6 & Other \\
\hline & 1 & 0 & 1 & 0 & 11 & Chair \\
\hline & 1 & 0 & 1 & 1 & 13 & Chair \\
\hline & 1 & 1 & 0 & 0 & 1 & Other \\
\hline & 1 & 1 & 0 & 1 & 3 & Other \\
\hline & 1 & 1 & 1 & 0 & 8 & Other \\
\hline & 1 & 1 & 1 & 1 & 10 & Other \\
\hline
\end{tabular}

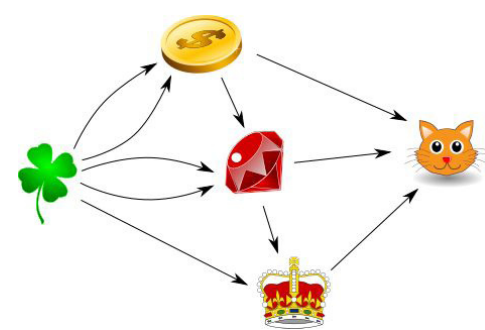

Fig. 3. Task "Beaver the alchemist". 
Question: How many clovers does Beaver the Alchemist need to create one kitten?
Answer:
A. 5 ,
B. 10 ,
C. 11 ,
D. 12

(Actually, this set of answers was presented to participants of 5-6 grades, elder participants had to input a number into the text box)

Explanation: The answer is 11 . We can see the conversion as follows:

$$
\begin{array}{lll}
\text { coin } & = & 2 \text { clovers } \\
\text { ruby } & = & 2 \text { clovers }+1 \text { coin }=4 \text { clovers } \\
\text { crown } & = & 1 \text { ruby }+1 \text { clover }=4 \text { clovers }+1 \text { clovers }=5 \text { clovers } \\
\text { kitten } & = & 1 \text { coin }+1 \text { ruby }+1 \text { crown }=2 \text { clovers }+4 \text { clovers }+5 \text { clovers } \\
& =11 \text { clovers }
\end{array}
$$

The answer 5 is for those who did not read the graph properly to realize that we need 2 clovers to create a coin or ruby, or for those who did not realize that you need a coin to create a ruby or a ruby to create a crown. The answer 10 is for those who think that the number of clovers is the same as the number of edges. The answer 12 is for those who miscounted.

\section{It's informatics:}

This task demonstrates how graphs can be used to represent dependencies between items. A graph is a data structure that is used a lot in informatics to demonstrate relationships. The graphs also make it easier to visualize a task compared to just reading the descriptions of the relationships in the text.

Note, that the scores system of the BEBRAS contest assumes subtracting one third of scores for a task in the case of a wrong answer. Simple evaluations demonstrate that a random choice of an answer will give at the average the same result as the refusal to give any answer (select "I don't know"), thus, the refusal to solve cannot be explained by a "strategical" considerations of a participant. The analysis (Yagunova and Ryzhova, 2013) showed, that there are two objective characteristics of a task: its hardness and its complexity. Assuming only participants who started to work with a task, the complexity is a percentage of participants who selected the answer "I don't know", and the hardness is a percentage of participants who did not give the correct answer. Fig. 4 demonstrates

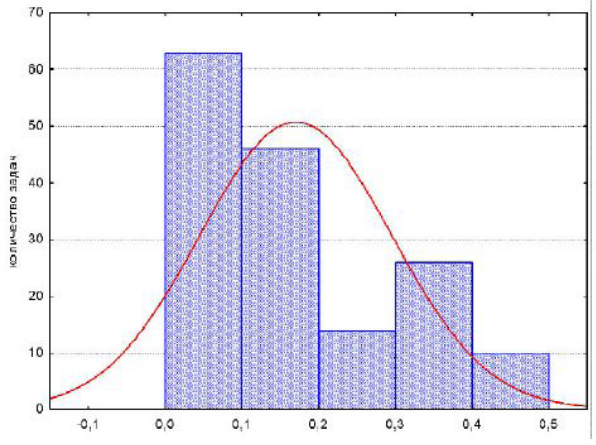

a

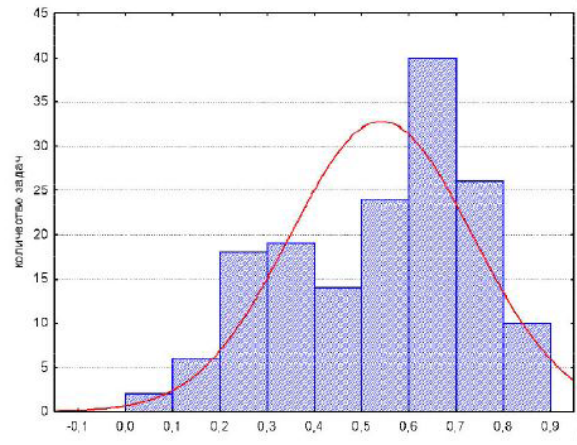

b

Fig. 4. Distribution of tasks by complexity (a) and by hardness (b). 
the distribution of BEBRAS tasks by complexity and by hardness (for the $2012^{\text {th }}$, the first BEBRAS year in Russia).

The distribution differs from the normal and has an apparent left asymmetry for the first one, and a right asymmetry for the second. This means that the tasks of the contest that year seemed not complex for participants, but occurred to be harder, that they thought.

For tasks authors, such distributions say a lot: they show, that the authors managed to overcome an entry barrier, i.e. they managed to express the task's statement in the way that seemed understandable for participants and made them ready to solve a task.

\section{Software Support of a Competition: Main Principles and their Implementation}

The Bebras contest is supported by a specially designed competitions system called DCES (Distance contests execution/educational system, implemented in Java, Play framework and MongoDB). It is designed to support different types of competitions with different regulations. One of the other competitions held by the system is a CTE contest (Posov and Maytarattanakhon, 2014). To implement some competition, one should use corresponding types of tasks, specify the process of collecting answers for separate tasks and the process of merging them into the result of a competition, set up a timing with the set of actions available for participants during different time segments. Everything that follows assumes only the Bebras contest.

There are two types of tasks used by the Bebras contest. The first is a simple choice of an answer from four presented variants. A participant may always select the fifth special variant "I don't know", if her or she does not want to give an answer. This is important, because rules specify that the wrong answer should subtract a certain number of scores.

The second type of a task is a dynamic task. These are the tasks that have arbitrary interaction, which should be implemented in almost pure JavaScript by a task author. There are libraries that automate the implementation of tasks with drag-and-drop interaction, such tasks usually ask to drag objects to the correct place. And there is a library to implement problems with a text field for an arbitrary text answer. One can adjust the input mask and a reaction to an incorrect input.

All dynamic problems also allow a participant to say "I don't know", the interface makes it obligatory for a participant to press a button "provide an answer" after he or she makes his or her actions to a task. After this button is pressed, he or she may press the button again to remove an answer and thus say "I don't know".

All tasks used in Bebras contest are entered into the system before the competition by filling the following fields: a statement, a question, a set of answers or an interaction depending on the task type, an explanation containing the correct answer, "It's informatics" section, that explains to a participant, how the task is connected to informatics. This separation to fields corresponds to the way the task is prepared by the international workgroups. 
The competition is held online, and participants read problems and enter answers with computers. This means that the system has certain requirements to storage stability of answers given by participants. All answers are sent to a competition server as soon as they are given by a participant. If a computer goes offline, answers are stored in a local storage and are sent to the server as soon as computers goes online again, even if it goes online after the competition has finished. Thus, any page reloading, computer reboot does not make answers lost. It is impossible to extend the time given to a participant (40 minutes) due to technical problems on a participant's side, the only possible thing is to reset all participation data for a participant and allow him or her to participate again.

The system supports highly configurable user roles. Roles usually include participants of a competition, school organizers that manage participants from their schools, higher level organizers, that manage school organizers, etc. The roles hierarchy differs for different competitions, and even in the Bebras contest in Russia and in Belarus, it depends on the established participant registration process.

\section{An Experience of the Contest Execution in Russian Federation}

In Russia, the Bebras contest is held within a program of Russian academy of education called "Productive education for everyone" and addresses the following aims:

1) To develop an interest to informatics, discrete mathematics and information culture.

2) To enable everybody who wants to participate and to achieve some success. A motivation for such communion is a game component and a week depending on achievements in school informatics, thus tasks are mainly aimed at quickness of wit and intuition.

3) To enable schoolchildren, who are considered making week progress for various reasons, to express themselves. That is why contest tasks differ from tasks suggested to them in informatics lessons, and are not connected to any specific curriculum in informatics or textbooks.

4) To help teachers to improve their qualifications.

The organization of the Bebras contest is held by the center of informatisation of education "CTE", operating on the basis of Saint Petersburg Electrotechnical University (ETU). To work with teachers and participants, the site with automated registration, contest execution and results processing (http://bebras.ru).

The faculty of computer science and technology works quite long on establishing a sequence of gradually complicating activities that lead a schoolchildren from a mass competition to an olympiad.

Currently, there are three stages, with the Bebras contest being the first:

1. Bebras: the mass contest on informatics.

2. "Construct, Test, Explore" (held about 15 years) (http://kio.spb.ru). The contest, presenting each year three nontrivial virtual laboratories, supporting re- 
search activity of schoolchildren. After the contest, these laboratories are used on teacher training courses and to support school sections on informatics.

3. The Olympiad in discrete mathematics and computer science for 9-11 grades (2016). The olympiad combines an idea of constructive work with computer models and tools with tasks, based on theoretical analysis of experiment results. The olympiad is held in December (the qualifying round) and March (the final round). In 2015-2016, 18 leading Russian universities participated as coorganizers.

All participants of the Bebras contest get a certificate with participation results. For those who are near to the top of the competition rating, their exact position in the rating is indicated, for others, their certificate does not contain this information. Fig 5. shows the poster with the information about the competition in 2015.

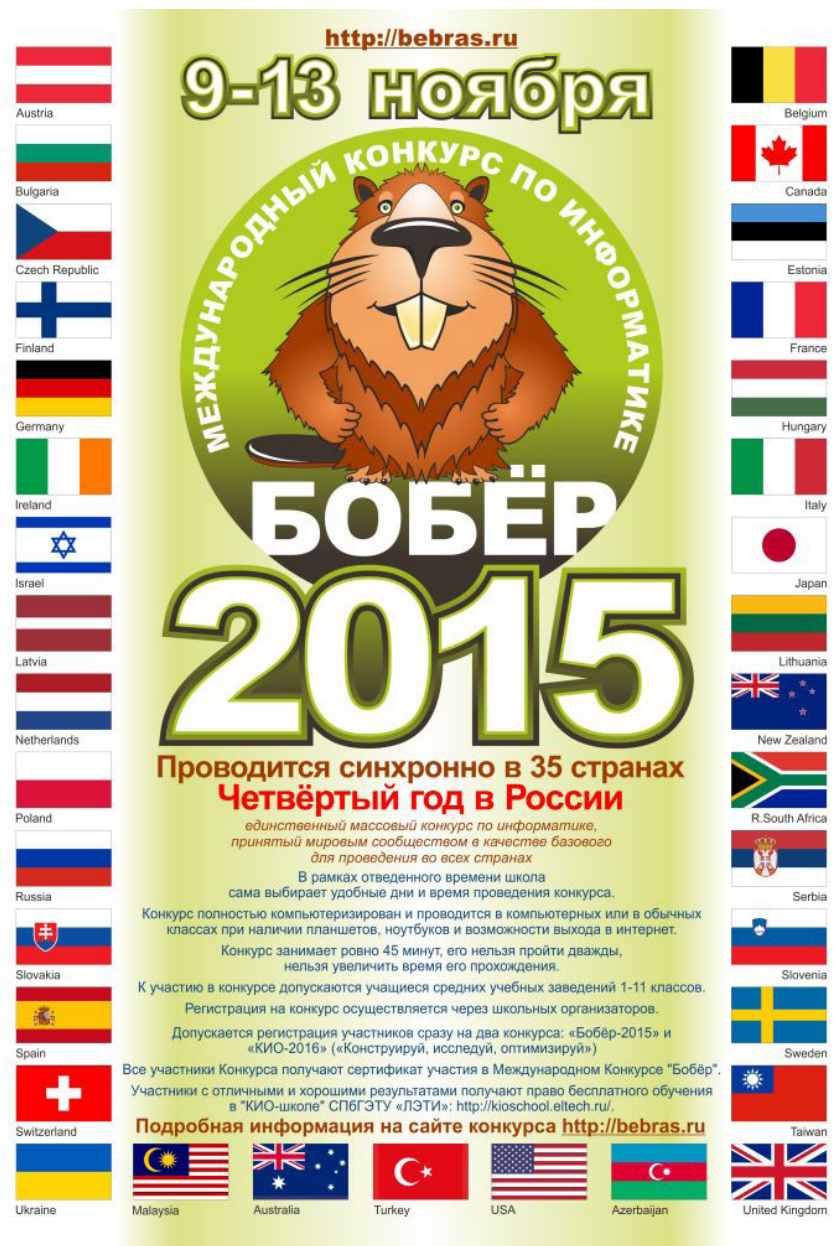

Fig. 5. Poster with an information about the Bebras contest in 2015. 


\section{An Experience of the Contest Execution in Belarus}

Understanding the importance of the development of schoolchildren interest in informatics and latest in programming, Belarusian State University of Informatics and Radioelectronics became a Belarus coordinator of the Bebras competition. Information support to the contest was provided by the Ministry of Education of Belarus.

The participation of Belarus schoolchildren in this important and significant event became possible thanks to the great help of colleagues, specialists from Russia, who, at this stage, provided technical and methodical support of the contest in Belarus.

In October, 2015, in Belarusian State University of Informatics and Radioelectronics, a two-days seminar for responsible coordinators of the contest from all regions of the republic. The seminar was held by a national Russian coordinator Sergei Pozdniakov.

About 60 thousand schoolchildren of 1-11 grades took part in the contest. The most active were participants from the Grodno region (14248 part.), the Brest region (9066 part.), and the Vitebsk region (8840 part.).

The organization and coordination of the Bebras contest in regions were conducted both by regional representatives, and also directly through the communication of school organizers with the Organizing Committee.

Belarus schoolchildren showed great interest in solving competition problems and demonstrated good results. Diplomas of the I, II, III grades were given to 2155 participants (2016), including 67 participants, who got the maximal scores, $81 \%$ of whom are from 3-4 grades. About 30\% winners of the contest got the diploma of the I grade. Significant are the results of participants from the $1-2$ grades, $27 \%$ of their winners got a diploma of the I grade, and also the results of participants of 7-8 grades, $32 \%$ of their winners got a diploma of the I grade.

\section{Conclusion}

A participation in such intellectual contests allows to encourage and improve motivation of schoolchildren in the usage of modern information-communication technologies, allows to improve the level of computer literacy of pupils, their algorithmic and computational thinking, and also to activate creative activity of teachers. This will then allow schoolchildren and their teachers to master new methods and algorithms for solving problems.

Important are the cognitive, social, cultural and intercultural aspects of the international contest.

The main feature of the contest is its coverage of younger schoolchildren, that is, it allows children motivated in informatics to make a start.

In the opinion of the expert in informatics olympiad in Russia, prof. M. S. Tsvektova, "informatics in the $21^{\text {st }}$ century experiences a transformation in contents, because a school becomes filled with the new generation of children: the generation Z. For these young schoolchildren informatics is an integral part of the digital world, surrounding 
them. That is why it is extremely important to give children an ability to find themselves in informatics by means of different intellectual competitions. The mathematical contest "Kangaroo" in 1-4 grades is very popular in Russian schools. But children are interested in doing something with computers. Thus, informatics in primary school has been already taught already since 1990. Informatics is included in the state educational standard of primary education (1-4 grades), there exists a handy curriculum for schools, various textbooks are developed. And, of caurse, there exist talented kids. That is why the development of contests for young schoolchildren is urgent. Russia has such an experience, these are contests "KIT", "Infoznayka", "Trizformashka", "Informashka", the contest on Scratch (2016). Because of these contests, children may become familiar with olympiads, and to show very strong results already in the $5^{\text {th }}$ grade.

Concerning olympiad movement in informatics for schoolchildren of 5-11 grades, it involves schoolchildren of our country within the all-Russian school olympiad that is held in the country on 24 school subjects. Among them, the all-Russian informatics olympiad has been held for 28 years. However, children of the 1-4 grades are not included in this movement.

It is very important to support children of primary school keen on informatics with various creative competition, but it is very hard without a partnership with teachers. It is important, that the Bebras contest the registration of a child-participant is done by his teacher or an instructor. We hope, that the Beaver competition will find its interested audience not only among children, but also among teacher of the primary school both in Russia and in commonwealth countries".

\section{References}

Bebras website (2016). http: //bebras.org/

Bebras in Belarus (2016). (In Russian). http://babior by/babior2015/main/go/p

Bebras in Russia (2016). (In Russian). http://bebras . ru

Center of Information Technologies in Education “CTE” (2016). (In Russian). http://ipo.spb.ru

Construct, Test Explore contest (2016). (In Russian). http://kio.spb.ru

Dagienè, V., Futschek, G. (2008). Bebras international contest on informatics and computer literacy: criteria for good tasks. In: R.T. Mittermeier and M.M. Syslo (Eds.), ISSEP 2008, Lecture Notes in Computer Science 5090. Springer-Verlag Berlin Heidelberg, 19-30.

Ivanov, S., Mamaeva S., Pozdnyakov S., Stepulenok D., Entina S. (2004). Computer support of educational research on mathematics. Computer Tools in Education Journal, 2, 5-18. (In Russian. Компьютерная поддержка дистанционного учебного исследования по математике. Компьютерные инструменты в образовании).

Kangaroo in Russia (2016). (In Russian). http://mathkang.ru

Olympiad informatics (2016). (In Russian). http://inf-olymp.ru/resources/informatics-in-school/

Olympiad on discrete math and theoretical informatics (2016). (In Russian). http: //dmti .ipo.spb.ru/

Posov, I., Maytarattanakhon A. (2014). Automation of distance contests based on research problems in mathematics and informatics. Computer Tools in Education Journal, 6, 45-51. (In Russian. Автоматизация проведения дистанционных соревнований, основанных на исследовательских сюжетах по математике и информатике. Компьютерные инструменты в образовании).

Yagunova, E., Ryzhova, E. (2013). The usage of protocols of online competitions for an assessment of complexity of tasks and increase of a validity of measuring procedure. Computer Tools in Education Journal, 6, 33-44. (In Russian. Использование протоколов он-лайн конкурсов для оценки сложности задач и повышения валидности измерительной процедуры. Компьютерные инструменты в образовании). 


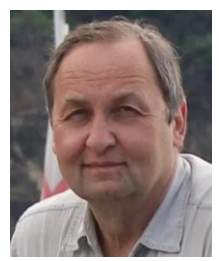

S.N. Pozdniakov, Professor of the Department of Mathematics, Faculty of Computer Science and Technology, Saint Petersburg State Electotechnical University, Doctor (Doktor nauk) of Pedagogical Sciences, associate professor of the Department of Informatics, Faculty of Mathematics and Mechanics, Saint Petersburg State University. He is founder and editor-in-chief of Computer Tools in Education Journal (publish from 1998), founder and scientific adviser of Construct-TestExplore Contest (founded at 2004) and Russian Olympiad in Discrete Mathematics and Theoretical Informatics (2013), organizer and task designer of Bebras contest in Russia.

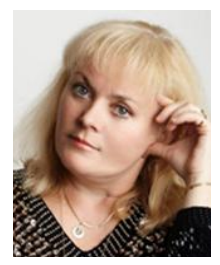

I.F. Kirynovich, associate professor of the department of engineering psychology and ergonomics, faculty of computer design, Belarusian State University of Informatics and Radioelectronics, PhD in Physics and Mathematics, national coordinator of the Bebras contest in Belarus, scientific and pedagogical leader for the preparation team of the Republic of Belarus for participation in the international Olympiad in Informatics.

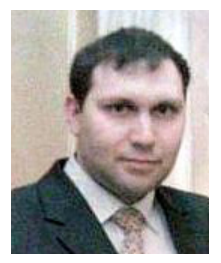

I.A. Posov, associate professor of the Department of Mathematics, Faculty of Computer Science and Technology, Saint Petersburg State Electotechnical University, associate professor of the department of information systems in arts and humanities, faculty of arts, Saint Petersburg State University, $\mathrm{PhD}$ in Technical sciences, author of software for supporting of contests in informatics and mathematics, task designer of Bebras contest in Russia. 